\title{
The present and future of clinical psychology in Germany
}

\author{
JUERGEN HOYER and HANS-ULRICH WITTCHEN
}

\section{INTRODUCTION}

This paper does not aim to predict the future of clinical psychology in Germany. The future of psychology depends on the complex interaction between political, sociological, economic and health-care related factors as well as on the scientific progress in the discipline itself and in neighbour disciplines. However, it is fair to say that clinical psychology continues to gain even stronger influences in health care and will face a number of new challenges over the next years of its expansion.

Our paper will present some of these potential fields of development and change based on a brief description of the status quo. The focus of the article will be specific developments in Germany, although there will be an overlap with general tendencies that describe the situation of clinical psychology in the new millennium in general. Furthermore, for research as well as practice, the specific relationship between clinical psychology and psychiatry will be highlighted.

\section{RESEARCH}

In the most recent presidential report for the Deutsche Gesellschaft für Psychologie (German Society for Psychology), Kluwe (2001) emphasized the following three challenges for research and practice of psychology and clinical psychology, in particular: internationalisation, interdisciplinary orientation, and focus on application.

\footnotetext{
Indirizzo per la corrispondenza: Dr. J.Hoyer, University of Technology Dresden, Clinical Psychology and Psychotherapy, D01062 Dresden (Germany).

Fax: +351-4636984

E-mail: hoyer@psy1.psych.tu-dresden.de
}

\section{Internationalisation}

More than before, internationalisation has become a key challenge in various ways, e.g., collaboration in international research activities such as in EU programs; the use of international (as opposed to national) research standards and instruments; a stronger commitment to internationally relevant research topics; publishing not only in German, but also in international journals. Although part of this agenda has already been implemented successfully as exemplified by the widespread use of the DSM-IV (American Psychological Association, 1996) in German clinical psychological research, other parts are still lacking.

For example, among German researchers, the German language is the most popular vehicle for communicating scientific findings; thus communication to countries that use other languages is sometimes restricted. The German scientific community is large enough to maintain its own journals in German. While this is, of course, practicable for German professionals, it impedes a stronger international orientation and does not ensure sufficient dissemination of basic knowledge and research findings obtained in Germany. (Who for example knows about the unique behaviour therapy provider characteristics and reimbursement schemes and problems in Germany?) Furthermore, such a situation hinders a harmonisation of graduate and post-graduate standards and models.

The German university system differs markedly from the Anglo-American one. It bestows no bachelors or masters degree. Instead, there is a university diploma (approximately 5 years duration) that allows for some professional qualification in fields such as clinical or psychological psychotherapy and includes an empirical or experimental diploma thesis. Scientific research depends heavily on subsequent dissertations (3 years duration). Qualification toward professorship includes not only the doctoral dissertation, but also a "Habilitation," which usually demands - along with teaching and scientific peer 
reviewed papers - a series of empirical studies based on an original approach, a task that usually takes about six years.

These time-consuming standards do not make German universities very attractive for international students and slow down progress in excellent research and international collaboration. The stepwise adaptation of the German university system to standards that provide a more appropriate match to other countries is, accordingly, a major mission which is currently recognized (Kluwe, 2001) and at some universities structural changes have already been decided.

\section{Interdisciplinary orientation}

During the last two decades, most scientific disciplines have softened the traditional boundaries between psychology, medicine, genetics, and biology. Clinical psychological questions and mental health issues are no longer investigated by psychology and/or psychiatry alone but also by disciplines such as behavioural medicine, public health, neurobiology, clinical neurosciences, neuropsychophysiology, biogenetics, and others. As these fields have developed their own identities and as clinical psychology has so far been unable to provide a metatheory of the field, the unity of clinical psychology may be regarded as threatened (Baumann, 1997, 2000). On the other hand, clinical psychological research competence (e.g., with regard to elaborate integrative psychological models and advanced bio-statistical methods as well as its unique techniques and strategies in psychotherapeutic interventions) is higher than ever. Also, new fields of intervention beyond psychotherapy are opening up for psychologists (see below).

\section{Research perspectives}

Results of interdisciplinary research have made it increasingly clear that mental disorders as a key component of the agenda of clinical psychology can be adequately understood only by a multidisciplinary approach that integrates the neurobiological bases of behaviour with cognition and affect. For example, disinhibited neurobiological functions or, more rarely, lesions with a neurobiological substrate are not necessarily due to somatic or genetic (thus, "medical") causes; they can also refer to early trauma (Aldenhoff, 1998) as well as to other psychosocial, developmental and physical influences. Changes in these neurobiological functions can be suc- cessfully achieved, for example, by pharmacotherapeutic as well as psychotherapeutic treatments (Aldenhoff et al., 1997). These findings helped bridge the gap between fundamentalistic proponents of nature (psychiatrists?) versus nurture (psychologists?) and made the mindbody dichotomy obsolete.

As another prominent development, testing the efficacy and effectiveness of clinical intervention has become a standard not only in medical settings but also in psychotherapy. Yet, unlike drug treatments, there is no structurally secure financial basis for research on psychotherapeutic and other psychosocial interventions (Margraf, 2000). Pharmaceutical innovations are costneutral, if previous research efforts are re-financed by the price of new medicaments. But who pays for the better evaluation of new psychotherapeutic treatments? Although support on the political level is weak, there is no alternative to treatment research using high methodological standards, particularly if the formation of a more professional impression of behaviour therapy or psychotherapy in general is intended. And even at the beginning of the new century this is still a clear necessity, as the difference between scientifically validated and simply intuitive or esoteric treatments is seldom acknowledged by the general public (Margraf, 2000).

\section{PRACTICE}

In comparison to the unclear and insecure legal status of psychologists as health professionals in the 80's (Brengelmann \& Wittchen, 1986; Fichter \& Wittchen, 1980; Wittchen \& Fichter, 1980), a key change has been achieved by the new professional status as "psychological therapists" by law (Psychotherapeutengesetz, 1999; Bundesministerium für Gesundheit, 1998). This change will affect the university course and post-graduate training in clinical psychology as well as the self-definition of the discipline which now has been re-labelled as "Clinical Psychology and Psychotherapy" by most university institutes in Germany.

\section{A new legal status for psychological psychothera- pists: a Pyrrhic victory ?}

The new law specifies that clinical psychologists can register as "Psychological Psychotherapists" within the national health insurance system, making psychotherapy accessible to all mandates at no cost. This registration requires completion of a 3-year fulltime post- 
graduate training in specially licensed institutions. For more than 20 years (the first draft of the law for psychotherapy as a profession was tabled in 1978), German clinical psychology fought for such a legal status comparable to the one of medical doctors. Now that this potential "begin of a new era" (Strauß, 1998) has finally been achieved (at 1.1.1999), the consequences of this breakthrough are not yet quite clear. From a psychological perspective, a first evaluation must take the high costs into account that the legal compromise implies for the profession and indicates a problematic prognosis. The most important negative implication is the limitation ("freezing") of the costs for psychological psychotherapy ( $1 \%$ of the medical health care budget). Furthermore, the number of private psychological therapists was limited for the first time by region. As a result, their earnings have dramatically dropped (especially in Berlin and Saxonia) and are estimated to be about $42 \%$ lower than in other industrialized western countries (Siefen \& Kirkcaldy, 2000). They are also clearly lower than in most other academic professions in Germany. As a consequence, the motivation for students to qualify in psychological therapy might be reduced. If this turns out to be true, the significance of clinical psychology as a whole will be threatened. This development is particularly problematic given the high rates of psychiatric morbidity found in recent studies, e.g., the Munich Community Study, and the high rates of unmet need for adequate treatment (Wittchen, 2000; Wittchen \& Jacobi, in press). Although a total number of 29.010 colleagues received the legal status as "psychological psychotherapists," and 13.025 of these participate in the health insurance services (data of spring 2000; Deutsche Gesellschaft für Verhaltenstherapie, 2000), there are still problems in the provision of adequate psychotherapeutic treatment for outpatients and, particularly, for children and adolescents (Deutsche Gesellschaft für Psychologie, 2000).

New legal initiatives (Gesundheitsreformgesetz, 2000) focus on prevention and health promotion including interventions such as exercise, diet, anti-stress training, and anti-smoking and drug abuse training in a group format. These interdisciplinary training approaches have been shown to be highly effective, even from a cost perspective. Nevertheless, they are clearly not sufficient to reduce the large gap in providing adequate psychotherapeutic treatment. Additionally, the wellknown positive impact of psychological interventions on medical cost-offset (Chiles et al., 1999) has not led to a satisfying inclusion of clinical psychologists in routine care.

\section{Trend toward Behaviour Therapy}

By the end of 1998 about 4900 colleagues were licensed for behaviour therapy; of these, 3736 (three-quarters) were psychologists, and 1164 were medical doctors. At the same time, 12832 colleagues were licensed psychodynamic or psychoanalytical therapists; of these, 8571 (approximately two-thirds) were medical doctors, and only 4261 were psychologists (Hand, 2000). These data clearly demonstrate the specific attraction of behaviour therapy for psychologists, and the still intimate bond between psychoanalysis and psychiatry and other medical specialisations in the field of mental disorders.

Nevertheless, there is a general trend toward behaviour therapy, as the number of licensed behaviour therapists has risen about 100 per cent in the last decade (Hand, 2000). Probably this trend will endure, due to the higher pressure to apply empirically validated, flexible and cost-effective treatments also in psychotherapy, a development that in Germany was particularly promoted by the ground-breaking meta-analysis of psychotherapy research by Grawe et al. (1994).

However, regardless of its orientation, psychotherapy alone will not constitute a secure basis for the future of clinical psychology. As Russo \& Howard (1999) point out, "psychology has been slow to adopt a point-of-need service delivery model" (p. 237), for example in the psychosocial rehabilitation of chronic psychiatric disorder patients, since little training in these more specific approaches is done in current academic or practical curricula. Dating back to the 80 's (Brengelmann \& Wittchen, 1986), in Germany, continuous efforts towards specialty care by psychologists have been made, and at present some psychotherapy curricula and Universities of Applied Sciences provide specialized programs for qualification in fields such as neuro-psychology, rehabilitation, or forensic psychology.

\section{Psychology and psychiatry: collaboration, competition, and unawareness}

Those psychiatrists and psychologists who are psychotherapists are in competition regarding psychotherapy patients. However, since the two professions often have differing therapeutic orientations, they offer true alternatives to the patient, which may reduce the potential for conflict. Due to their strengthened legal status, clinical psychologists will become much more visible as health professionals and, by and large, become more accepted by medical colleagues in the field of men- 
tal disorders. This process will encourage more collaboration between both professions.

While there is at least some collaboration in research (for an overview see Baumann, 1997), each field - clinical psychology and psychiatry - seems to be largely unaware of current developments in the respective other area. A literature overview reveals only a few German publications on the relationship of psychiatry and clinical psychology in recent years (e.g., Schmidt, 1998). Dialogue is restricted and seemingly takes place only when there is a given need in research or practice. However, effective collaboration is possible: For example, metaanalytic data show that additional psychotherapeutic interventions among schizophrenics lead to incremental effectiveness compared with a purely pharmacological and unspecific psychosocial treatment (Wunderlich et al., 1996).

Initiatives for better networking between institutions and professions can be seen in specialized rehabilitation centers, "psychosomatic" clinics, or clinics for substance abuse disorders where a considerable part of the service is delivered by psychologists. Moreover, to avoid recidivism of these patients, a continuous treatment and collaboration between the clinic (often medical doctors) and private psychotherapeutic practices (often psychologists) is effective. This is now being more thoroughly recognized. There is hope that the need for better networking and continuous integrated care will also lead to a better integration and collaboration of professions.

\section{Other developments}

Clinical psychology remains the central professional field for psychologists (Baumann, 1997) and "psychological psychotherapists" play a major role in German psychiatric and psychotherapeutic services (Brengelmann \& Wittchen, 1986). This success may in part be due to the ability to adapt to new developments and needs. During the last two decades, clinical psychology had to move away from many older positions such as, e.g., a too critical standpoint toward nosological classification, namely in client-centered therapy. Similarly, operationalized clinical diagnosis has been recognized as a major step forward in psychodynamic therapy. Client-centered therapy and a number of other humanistic psychotherapy approaches generally have dramatically lost influence and attractiveness because they failed to be included as empirically validated treatments in the health insurance system. These are examples not only for an opening toward international developments, but also for faster communication in science in general. As an example: research data, patient reports and demonstrations, literature and training materials are all available in the internet (Eichenberg \& Ott, 1999).

At the first glance, it seems relatively clear what this will bring: more information, more integration, and less segregation; less specifically national developments and more internationally potent trends. But no matter whether we are clinical psychologists or psychiatrists, we also know that information processing - even in normal individuals - is and will always be selective and can be impaired, e.g., by personal or professional interests. It will strengthen their future perspectives if both clinical psychology and psychiatry work to counteract this human, but also irrational, tendency as much as possible.

\section{REFERENCES}

Aldenhoff J. B. (1998). Zukunftsperspektiven der Forschung in Psychiatrie und Psychotherapie. In Zwischen Spezialisierung und Integration - Perspektiven der Psychiatrie und Psychotherapie (ed. W. Gaebel and P. Falkai), pp. 127-138. Springer: Wien, New York.

Aldenhoff J. B., Dumais-Huber C., Fritzsche M., Sulger J. \& Vollmayr B. (1997). Altered Ca(2+)-homeostasis in single T-lymphocytes of depressed patients. Journal of Psychiatric Research 31, 315-322.

American Psychological Association (1994). Diagnostic and Statistical Manual of Mental Ddisorders, 4th ed. APA: Washington, DC.

Baumann U. (1997). Clinical Psychology in German-speaking countries. World Psychology 3, 437-463.

Baumann U. (2000). "Klinische Psychologie" versus "Klinische Psychologie und Psýchotherapie". Zeitschrift für Psychologie 208, 205 255.

Brengelmann J. C. \& Wittchen H.-U. (1986). Professional psychology and private health services: developing trends in the Federal Republic of Germany. American Psychologist 41(3), 306-308.

Bundesministerium für Gesundheit (1998). Gesetz über die Berufe des Psychologischen Psychotherapeuten und des Kinder- und Jugendlichenpsychotherapeuten, zur Änderung des Fünften Buches Sozialgesetzbuch und anderer Gesetze. Bundesgesetzblatt, Teil I, Nr. 36, 1311-1321.

Chiles J. A., Lambert M.J. \& Hatch A.L. (1999). The impact of psychological interventions on medical cost offset. Clinical Psychology 6, 204-220.

Deutsche Gesellschaft für Psychologie (DGPs) - Fachgruppe Klinische Psychologie und Psychotherapie (2000). Stellungnahme zur Anfrage des Sachverständigenrates für die Konzertierte Aktion im Gesundheitswesen zur bedarfsgerechten psychotherapeutischen Versorgung. Verhaltenstherapie und Psychosoziale Praxis 32, Suppl. 2, 6-9.

Deutsche Gesellschaft für Verhaltenstherapie (dgvt) (2000). Statistiken $\mathrm{zu}$ den Approbationen und Zulassungen von Psychotherapeuten. Verhaltenstherapie und Psychosoziale Praxis 32, Suppl. 2, 4-5. 
Eichenberg C. \& Ott R. (1999). Klinische Psychologie und Psychotherapie im Internet. Ein Wegweiser durch das WWW. Psychomed 11, 184-189.

Fichter M.M. \& Wittchen H.-U. (1980). Clinical psychology and psychotherapy. A survey of the present state of professionalization in 23 countries. American Psychologist 35, 1-26.

Grawe K., Donati R. \& Bernauer F. (1994). Psychotherapie im Wandel: Von der Konfession zur Profession. Hogrefe: Göttingen.

Hand I. (2000). Verhaltenstherapie - Mit dem ersten Dezennium ins neue Millenium. Verhaltenstherapie 10, 4-5.

Kluwe R. (2001). Zur Lage der Psychologie: Perspektiven der Fortentwicklung einer erfolgreichen Wissenschaft. Psychologische Rundschau 52, 1-10.

Margraf J. (2000). Verhaltenstherapie, Öffentlichkeit und Forschung. Verhaltenstherapie 10, 152-153.

Russo D.C. \& Howard, H.A. (1999). The evolving role of clinical psychology in health care systems. Clinical Psychology 6, 232-238.

Schmidt L.R. (1998). Psychiatrie-Reform und Klinische Psychologie. Report Psychologie 23, 630-641.
Siefen G. \& Kirkcaldy B. (2000). Internationaler Vergleich von Psychotherapiehonoraren als Orientierungshilfe. Psychotherapeut 45, 249-252.

Strauß B. (1998). Psychologische Psychotherapie - Beginn einer neuen Ära? Psychotherapie Psychosomatik \& Medizinische Psychologie $48,155$.

Wittchen H.-U. (2000). Met and unmet need for interventions in community cases with anxiety disorders. In Unmet Need in Psychiatry. Problems, Resources, Responses (ed. G. Andrews and S. Henderson), pp. 256-276. Cambridge University Press: Cambridge.

Wittchen H.-U. \& Fichter M.M. (1980). Psychotherapie in der Bundesrepublik (Psychotherapy in the Federal Republic of Germany). Beltz: Weinheim.

Wittchen H.-U. \& Jacobi F. (in press). Häufigkeit und Behandlungsstatus psychischer Störungen in Deutschland. Psychologische Rundschau.

Wunderlich U., Wiedemann L. \& Buchkremer G. (1996). Sind psychosoziale Interventionen bei schizophrenen Patienten wirksam? Eine Metaanalyse. Verhaltenstherapie 6, 4-13. 